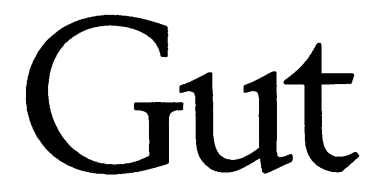

Editorial

\title{
Research misconduct
}

Fraud in science has been with us for many decades ${ }^{1}$ but despite the wide spread publicity directed towards a few major cases of research fraud, the scientific community has been, perhaps, falsely reassured by estimates that $99.9 \%$ of published science is untainted. Stephen Lock, while Editor of the $B M F$ in 1988, began the expose in Britain which he suggested that the problem was more extensive and that the cases detected represented the tip of a large iceberg. ${ }^{2}$ While others have picked up the baton, Britain has been slow to develop procedures to detect and punish offenders, although proposals for prevention have come forward from the Royal College of Physicians. ${ }^{3}$ Some countries such as the United States of America, Denmark, Finland, Norway, Austria, and Australia have developed mechanisms for dealing with these problems, and I believe that many editors of medical journals in the United Kingdom now feel that we should put similar measures in place.

I have been prompted to write this editorial because during my first year as Editor of Gut, I and the Associate Editors have detected four instances of research misconduct, including plagiarism, duplicate (redundant) publication and the submission of a paper to several journals simultaneously without the knowledge of a coauthor. I shall briefly describe these case histories and the action that we took in dealing with the problem.

The first case was one of overt plagiarism. The paper described aspects of mucosal immunology in Helicobacter pylori associated gastric ulcer; both reviewers rejected the manuscript on scientific grounds. Fortuitously, one of the reviewers recognised large blocks of text which had been lifted verbatim from two of his/her own published papers. The plagiarised material accounted for $75 \%$ of the discussion section of the submitted manuscript. The reviewer, whilst maintaining a sense of humour, stating "I am aware that imitation is the sincerest form of flattery," advised us rightly that this should be pointed out to the authors in no uncertain terms. I wrote to the corresponding (senior) author rejecting the paper and at the same time pointing out the extensive plagiarism. I eventually received a reply following a reminder one month later when the plagiarism was acknowledged and attributed to the inexperience and junior status of the first author. An internal institutional enquiry was held and the results reported to us. We were satisfied that the authors had been suitably reprimanded and counselled within their department by a senior academic. We felt we could take the matter no further.

The second case was that of redundant publication. Redundant publication (sometimes referred to as duplicate publication) is publication of a paper that overlaps substantially with one that has already been published by the same authors. The topic in this case was gastrooesophageal reflux. The manuscript was assessed by two reviewers; both considered the paper of interest but the first reviewer was concerned about the design of the study and advised rejection. The second reviewer recommended acceptance with revision, but pointed out both in the comments to the authors and in those to the editor that the paper had already been published a few months previously in another journal. On comparing the new manuscript with the previously published paper, overlap was estimated to be at least $80 \%$. The amount of new information provided was minimal and did not change the message of the paper in any way. The letter accompanying the manuscript sent to Gut appeared to carry the signatures of all of the co-authors, all but one having authored the previously published article. The paper was rejected and research misconduct pointed out to the corresponding author with a request for comments and an explanation from all authors. After a delay of five weeks and a reminder, a reply was received which conceded duplicate publication. The third case was in the field of mucosal immunology and again amounted to redundant publication but in a less overt and serious form as that described in case two. The paper was rejected and the reasons clearly pointed out in the rejection letter.

Case four was an uncontrolled trial of a novel therapy in a small group of patients with inflammatory bowel disease. Following consideration by myself and the Associate Editors, we decided to reject the manuscript without inviting the opinions of external reviewers because of the preliminary nature of the paper and fundamental flaws in the methods. Rejection letters were sent to both authors but within a matter of days we received a fax from the second author indicating that he had not seen the article, had not been involved in its preparation, and had not given consent to be a co-author. In subsequent correspondence the first author apologised for the misdemeanours, indicating an absence of knowledge regarding the conventions of not submitting a paper simultaneously to more than one journal and the requirements of authorship. This case, and perhaps the inexperienced author in case one, illustrates the need for institutions and principal investigators to provide clear guidance on the ethics of research and publication. Education should begin in medical school and remain part of continuing medical education.

In addition to these cases we have detected several instances of "salami slicing". This process is well known to editors whereby a single study is converted into several papers by publishing the data piecemeal. A good example 
from our experience is an immunohistochemical study in which a series of monoclonal antibodies was used to detect mucosal cytokine expression - each monoclonal antibody and thus each cytokine became a "slice of salami" and thus a separate paper. In most instances this is undesirable as it increases quantity and decreases quality.

It might be argued that none of these examples of research misconduct are serious and that no harm has been done as all were detected prior to publication. No retractions have been required and no authors have faced public disgrace as we have not and do not intend to identify them on this occasion. Our difficulty as editors is that there is no organisation or agency to which we can refer such cases, and other than pointing out misconduct to the authors, we have no powers to take the matter further. However, if publication had occurred and retraction of redundant publication was required, then public revelation would have been inevitable. Similar action would have been appropriate if plagiarism had only been detected after publication. Our concern is that these are the detected cases, but how many have escaped the vigilant eyes of reviewers and editors? How many cases of more serious research misconduct, such as data fabrication, have we missed?

During the past 12 months, the pace has begun to quicken. In March 1996, Richard Smith, Editor of the $B M F$, appealed to the British medical profession to tackle research misconduct in an editorial, "Time to face up to research misconduct". ${ }^{4}$ A similar editorial appeared in the Lancet in the same weeks, the editors of both journals wishing jointly to challenge the biomedical scientific community to "pick up the gauntlet". At the end of 1996 Michael Doherty, Editor of Annals of the Rheumatic Diseases, published a "hardline" editorial on how the journal planned to deal with redundant publication. ${ }^{6}$ Earlier this year, Geir Jacobsen, Professor at the Norwegian University of Science and Technology, published an editorial in the fournal of the Royal College of Physicians, "Do we need a research police", 7 which accompanied a transcript of a lecture given by Stephen Lock to the College on fraud in medical research. ${ }^{8}$ In February 1997 Peter Wilmshurst, Consultant Cardiologist in Shrewsbury, authored an alarming column, "The code of silence", in which he charts the lamentable way in which the profession has denied research misconduct and in many cases concealed fraud even when the case has been proved beyond reasonable doubt. ${ }^{9}$

I, the Associate Editors and the Editorial Board are currently considering our position on research misconduct. We shall be developing detailed guidelines as to how we propose to prevent and detect fraud and other forms of research misconduct, and plan to participate actively in a wider movement to deal with research misconduct at a national level.

\section{MICHAEL J G FARTHING}

fuly 1997

1 Kohn A. False prophets. Oxford: Blackwell, 1986.

Lock S. Misconduct in medical research: Does it exist in Britain? $B M \mathcal{F}$ 1988; 297: 1531-5

3 Royal College of Physicians of London. Fraud and misconduct in medical research. London: RCP, 1991.

Smith R. Time to face up to research misconduct. $B M F$ 1996; 312: 789-90.

5 Anonymous. Dealing with deception [editorial]. Lancet 1996; 347: 843. 6 Doherty M. The misconduct of redundant publication. Ann Rheum Dis 1996; 55: 783-5.

7 Jacobsen G. Do we need a research police? $\mathcal{f} R$ Coll Physicians Lond 1997; 31: 8-9.

8 Lock S. Fraud in medical research. $f R$ Coll Physicians Lond 1997; 31: $90-4$.

9 Wilmshurst P. The code of silence. Lancet 1997; 349: 567-9. 